\title{
Same, same, but different? A longitudinal, mixed-methods study of stability in values and preferences for future end-of-life care among community-dwelling, older adults
}

\author{
Malin Eneslätt ${ }^{1,2^{*}}$, Gert Helgesson ${ }^{1}$ and Carol Tishelman 1,3,4
}

\begin{abstract}
Background: End-of-life preferences may change over time, e.g. due to illness progression or life events. Research on stability of end-of-life preferences has largely focused on life-sustaining treatments in seriously ill patients or medical decision-making based on hypothetical illness scenarios and possible treatment options. Few studies focus on community-dwellers in natural settings. The aim of this study was thus to explore if and how community-dwelling, older adults' prioritizations and reasoning about values and preferences for future end-of-life care change over time.

Methods: Using a mixed-methods design, we explored stability of end-of-life preferences in older communitydwelling adults without imminent end-of-life care needs. At two timepoints (T1 and T2), 5.5-12 months apart, 52 individuals discussed what would be important to them at the end-of-life, through open conversations and while using DöBra cards, a Swedish version of GoWish cards. Participants ranked their most important card statements from 1 to 10 . Stability in card rankings, i.e. a card recurring in the top-10 ranking at T2 regardless of position, was explored using descriptive statistics and non-parametric analyses. Participants' reasoning about card choices were explored with longitudinal qualitative analysis.
\end{abstract}

Results: Stability between T1 and T2 in the top-10 priorities ranged from 20 to $80 \%$, median $60 \%$. Stability in cards rankings could not be explained by changes in participants' health status, extent of card use (no/little/frequent use) between interviews, or days between T1 and T2, nor was it related to demographic variables. Qualitative analysis showed that consistent reasoning was not always paired with consistency in card choices and changed card choices were not always related to changes in reasoning.

Conclusions: Longitudinal exploration combining DöBra card rankings with underlying reasoning about endof-life preferences over time furthers knowledge on the dynamics between values and preferences in end-of-life decision-making. Individuals' end-of-life preferences in form of card choices were relatively stable over time albeit with large variation between different individuals. However, the values and underlying reasoning that participants used to motivate their choices appeared more stable than ranking of card choices. We thus conclude that concurrent conversation-based exploration is a more comprehensive indicator of end-of-life values and preferences over time than ranking of cards alone.

\footnotetext{
*Correspondence: Malin.Eneslatt@ki.se

1 Department of Learning, Informatics, Management and Ethics,

Karolinska Institutet, 17177 Stockholm, Sweden

Full list of author information is available at the end of the article
} original author(s) and the source, provide a link to the Creative Commons licence, and indicate if changes were made. The images or other third party material in this article are included in the article's Creative Commons licence, unless indicated otherwise in a credit line to the material. If material is not included in the article's Creative Commons licence and your intended use is not permitted by statutory regulation or exceeds the permitted use, you will need to obtain permission directly from the copyright holder. To view a copy of this licence, visit http://creativecommons.org/licenses/by/4.0/. The Creative Commons Public Domain Dedication waiver (http://creativeco mmons.org/publicdomain/zero/1.0/) applies to the data made available in this article, unless otherwise stated in a credit line to the data. 
Keywords: Advance care planning, End-of-life care, End-of-life conversations, Values and preferences, Mixedmethods, DöBra, Go Wish, Go-wish

\section{Background}

The European Association for Palliative Care has broadly defined advance care planning (ACP) as a process of reflecting on and making decisions for future end-oflife care [1]. It has been reported to positively impact the quality of end-of-life care, increase the proportion of goal-concordant care at the end-of-life, and lower hospital readmission rates [2-4]. However, there is a need to better understand how stable end-of-life preferences are over time, given that they may change, e.g. due to illness progression or life events $[5,6]$. Previous research on stability of preferences for future end-of-life care has largely focused on preferences for life-sustaining treatments in seriously ill patients [7-10].

A comprehensive review [11] found that individuals' end-of-life preferences were generally stable over time as well as after changes in health status, with this tendency more pronounced among seriously ill patients and inpatients than community-dwelling adults. However, another important finding was large variability in stability of end-of-life preferences among different studies. Although most studies evaluating direction of changes in end-of-life preferences indicated wanting less aggressive medical treatment over time and as an illness progressed, some studies reported contradictory findings [11]. A longitudinal study of preferences for life-prolonging vs. comfort care among patients with advanced cancer also showed inconsistent and unpredictable changes in preferences, suggesting high individual variation [12]. Longitudinal studies of community-dwellers' end-of-life care preferences are scarce, focusing primarily on stability of preferences for discrete medical treatments at the endof-life [13, 14] or euthanasia [15].

In the Advance care planning in Sweden (SweACP) project, we have examined end-of-life values and preferences broadly. SweACP, part of the DöBra ${ }^{1}$ research program [16], is a nation-wide research project planned and conducted in collaboration between a transdisciplinary team of researchers and representatives of national, community-based patient and interest organizations: the Association of Relatives to Cancer Patients, the Dementia Association, the Lung Cancer Interest Organization, Network against Cancer, the Swedish Association for Senior Citizens (SPF), and the Swedish National Pensioners' Organization (PRO). We engaged community-dwelling

${ }^{1}$ DöBra is a Swedish pun, meaning both 'dying well' but also 'awesome'. older adults who were not known to be at the end-oflife in conversations about what they thought would be important to them in their future end-of-life care, stimulated by a Swedish adaptation of GoWish cards [17]. In line with the card statements, we made efforts to address the overall life situation of a dying person instead of focusing solely on medical treatments. This approach was in part a product of possibilities that the ACP-naïve Swedish context presents, where documentation of endof-life preferences in the form of advance directives is briefly mentioned in the Swedish national guidelines for palliative care [18], but ACP is rare in Swedish health care settings. ACP is furthermore virtually unheard of among the general public, and documentation of end-of-life care wishes, or appointment of proxy decision-makers is not legally binding. It was also in part a concerted choice, based on previous international research, to develop an early [19], community-based [20], conversational ACP approach to stimulate processes of reflection and continued conversation [21] rather than medical decision-making and documentation of treatment preferences.

As previous studies about stability of end-of-life preferences primarily engaged participants in medical decisionmaking based on pre-formulated illness scenarios and possible treatment options [13, 14], there is need for further research in natural settings [11]. The GoWish/DöBra cards support clarifying real-world values as participants reflect about their own values and preferences for future care rather than considering set hypothetical scenarios. Two studies have examined stability of preferences using the GoWish cards; however, one was limited to comparing preferences in people with and without dementia [22] and the other had a narrow measurement window, studying preferences expressed only $4-24 \mathrm{~h}$ apart [23].

We therefore attempt to fill several important gaps in the literature as this study involves community-dwelling older adults, an understudied population, and longitudinally explores broad end-of-life values and preferences using a translated and adapted Swedish version of GoWish cards. Furthermore, we study not only stability of ranked card preferences but also reasoning underlying these choices. This could further the understanding of how to interpret previously stated end-of-life preferences, e.g. when an individual has lost capacity to express their wishes. Providing insights into motivations behind expressed preferences can be helpful for both health care staff and families in grappling with future care decisions, even ones which were never specifically addressed when 
the individual had capacity. The aim of this study is thus to explore if and how community-dwelling, older adults' prioritizations and reasoning about values and preferences for future end-of-life care change over time.

\section{Methods}

Using a longitudinal, mixed-methods design we compared future end-of-life prioritizations and reasoning about these at two timepoints (T1 and T2) using descriptive statistics and non-parametric statistical analyses to explore stability in card rankings, and longitudinal qualitative analysis to explore changes and similarities in reasoning over time. Definitions and operationalizations of the concept of stability are furthered described under 'Data Analysis'.

\section{Data collection}

The SweACP project focused on engaging older, community-dwelling adults without imminent end-of-life care needs in conversations about future end-of-life care. After receiving ethical approval (Stockholm, \#2015/106-31/5) study information was disseminated through the collaborating community organizations and a recruitment strategy based on active volunteering undertaken, with those interested in participating contacting the researchers. Written informed consent was provided. The only eligibility criteria were cognitive function that allowed understanding of informed consent and completion of the interview protocol, as well as being able to communicate in Swedish. Given the lack of formalized ACP initiatives in Sweden mentioned above, previous experience of end-of-life/ACP discussions was not a prerequisite. Purposeful and snowball sampling was used; a flowchart of recruitment and participation is shown in Fig. 1.

Between May 2015 and January 2018, two audiorecorded interviews were conducted with each participant 5.5 to 12 months apart. This timeframe was chosen to complement previous research [22, 23], and to allow for significant life events which may alter end-of-life values and preferences to occur, as well as reduce likelihood of participants' rankings being based on memory from the 1st interview. Interviews were held by one of two female research assistants, previously unknown to participants, with experience in conducting research interviews and MSc in Nursing (ME) and Forensic Psychology $(\mathrm{TJ})$. While conversational in nature, interviews followed similar protocols at $\mathrm{T} 1$ and $\mathrm{T} 2$. Issues of who and what participants thought would be important to them at end-of-life were initially explored through open-ended questions and subsequent prompts when needed. This was followed by a semi-structured interview section in which an EcoMap [24] was used to reflect on who would be important at the end-of-life (reported on elsewhere [25]). The GoWish cards had previously been found to be an intuitive, feasible tool to support end-of-life discussions in various settings in easing initiation of conversations by offering users something concrete to do with pre-formulated statements to consider that can be complemented by individualized 'wild cards' [17, 26-29]. An adapted Swedish version, the DöBra card deck, was therefore used to stimulate conversations about what would be important at the end-of-life.

With permission from and in collaboration with the developers (www.codaalliance.org), the U.S. GoWish

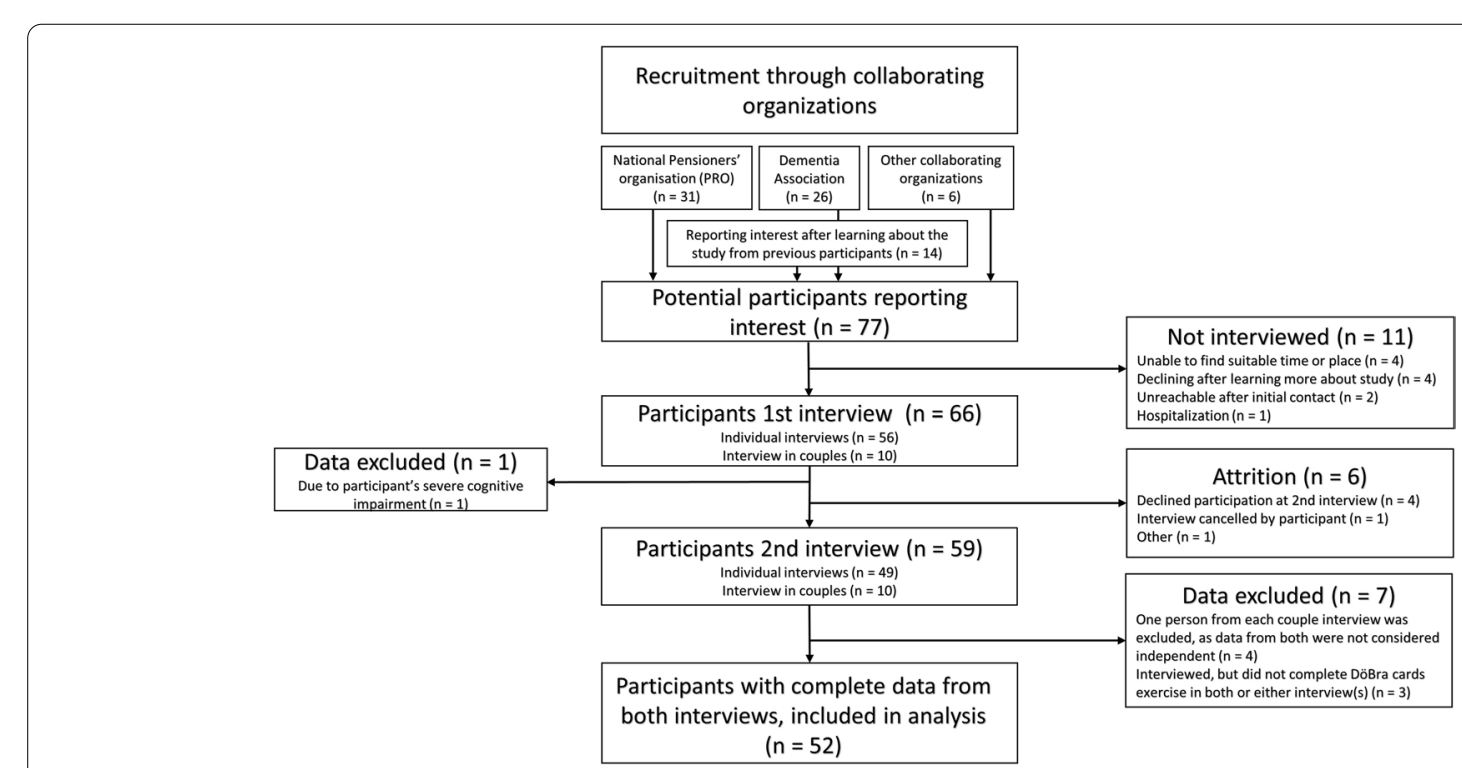

Fig. 1 Flowchart of recruitment and participation in interviews 
cards were translated and adapted to Swedish conditions by the SweACP project group, a process described elsewhere [25]. The DöBra cards contain 37 statements about that which may be important at end-of-life, and 'wild cards' for users to freely formulate other matters of importance (see Supplementary File 1). Participants sorted DöBra cards into three piles from most to least important and then ranked their ten most important card items from 1 to 10 . This ranking was photo-documented by the interviewer. Participants were encouraged to reflect on their choices throughout the exercise, thus generating data about their reasoning process while ranking card statements. Interviews were professionally transcribed verbatim and reviewed by the interviewer.

\section{Data analysis}

A mixed-methods approach was applied to data analysis to gain a comprehensive understanding of individuals' card rankings as well as their reasoning about their endof-life values and preferences. We adhere to the GRAMM guidelines [30] for reporting on mixed-methods studies.

We applied a definition of stability in card rankings as a DöBra card item remaining in the individual's top-10 ranking at both timepoints, regardless of specific rank. This has been used by comparable studies [22, 23]; and also matched our experiences from the card sorting exercise in the interviews. Wild card formulations were examined individually and judged stable when similar formulations recurred and as changed when formulations substantially differed between timepoints. The stability of each individual's ranking was calculated as a percentage of number of recurring card items divided by the maximum number of cards ranked at either timepoint. For example, four identical card items in the top-10 rankings with 10 cards prioritized in both interviews equaled $40 \%$ stability. When an individual had not ranked 10 cards in either interview, the number of recurring card items was divided with the maximum number of cards ranked in either interview. Due to the relatively small sample size, we used non-parametric analyses - Mann Whitney U-test, Kruskal-Wallis $\mathrm{H}$ test and Spearman's correlation test - to explore associations between the 52 participants' characteristics and stability in card rankings.

Inspired by Saldaña [31], we employed longitudinal qualitative analysis to a sub-sample to explore change in data through time. Data from four of the participants with the most (80\%) and the four with the least (20-33\%) stable card rankings were first analyzed. We initially explored similarities in reasoning within each of these groups and whether the degree of stability in reasoning differed between groups. Since we saw little difference between groups, we continued analysis by "re-casing" in line with Sandelowski [32]. Re-casing shifted the analytic focus from comparing reasoning of individuals in groups with most/least stable rankings to comparing reasoning about specific consistent/inconsistent card choices. In addition to re-visiting data of the eight participants with high/low stability, data from four additional participants with varied stability (40-70\%), varying demographical features and extensive data on reasoning processes were added to analysis at this stage.

Analysis was performed with adapted 'analytic flip charts' [31] in a text document, collating data for each individual, including time elapse between interviews, demographic characteristics, field notes, and top-10 DöBra card rankings, as well as interview excerpts with reasoning about the same card statement from both interviews. Using framing questions suggested by Saldaña [31], i.e. "How has ranking and reasoning changed between T1 and T2?" and "What contextual conditions seem to influence changes in reasoning?", we compared individual participants' reasoning about identical and changed card choices at T1 and T2. As analysis of data from these 12 participants, a sample size commonly considered adequate for qualitative analysis [33], showed clear patterns in reasoning about card choices, we did not include additional data in our in-depth qualitative analysis. However, we thereafter reviewed the full data set to ensure that the remaining data did not change or contradict the conclusions drawn based on the subsample. First author ME was responsible for carrying out the analysis but engaged in frequent discussions with the other authors during the process to enhance credibility.

\section{Results}

\section{Sample characteristics}

While 65 participants were initially interviewed in the SweACP project, 52 of them completed both interviews with full records and were included in analysis for this study, as shown in Fig. 1. Demographic information of original participants not included in analysis are shown in Supplementary file 2. Participants will in tables and text below be referred to as P for 'participant', followed by their interview code. Sample characteristics are shown in Table 1 . Time between interviews ranged from approximately $5.5-12$ months (median $\sim 10$ months). As shown in Table 1, participants were asked for an assessment of their health status but otherwise not specifically queried about the presence of illnesses.

\section{Stability of DöBra card rankings}

In this sample, median stability in card rankings between timepoints was $60 \%$, ranging from 20 to $80 \%$, as seen in Table 2. Only four participants had $<40 \%$ stability and 27 participants showed $60-70 \%$ stability between timepoints. 
Table 1 Sample characteristics

\begin{tabular}{|c|c|c|}
\hline Characteristics & $\begin{array}{l}\text { Full sample }(N=52) \\
\mathrm{N}(\%)\end{array}$ & $\begin{array}{l}\text { Sub-sample for } \\
\text { qualitative analysis } \\
(N=12) \\
\mathrm{N}(\%)\end{array}$ \\
\hline Age, median (range) & $74(43-95)$ yrs & $75,5(65-88)$ yrs \\
\hline \multicolumn{3}{|l|}{ Gender } \\
\hline Female & $38(73,1)$ & $9(75,0)$ \\
\hline Male & $14(26,9)$ & $3(25,0)$ \\
\hline \multicolumn{3}{|l|}{ Living situation } \\
\hline Spouse & $23(44,2)$ & $2(16,7)$ \\
\hline Alone & $28(53,8)$ & $10(83,3)$ \\
\hline With children & $1(1,9)$ & $0(0,0)$ \\
\hline \multicolumn{3}{|l|}{ Education } \\
\hline University & $27(51,9)$ & $6(50,0)$ \\
\hline High school & $9(17,3)$ & $1(8,3)$ \\
\hline Elementary school & $12(23,1)$ & $4(33,3)$ \\
\hline Other & $4(7,7)$ & $1(8,3)$ \\
\hline \multicolumn{3}{|l|}{ Employment status } \\
\hline Retired & $44(84,6)$ & $12(100)$ \\
\hline Employed, part-time & $4(7,7)$ & $0(0,0)$ \\
\hline $\begin{array}{l}\text { Retired, working } \\
\text { part-time }\end{array}$ & $2(3,8)$ & $0(0,0)$ \\
\hline Student, full-time & $1(1,9)$ & $0(0,0)$ \\
\hline Employed, full-time & $1(1,9)$ & $0(0,0)$ \\
\hline \multicolumn{3}{|c|}{ Self-assessed health status ${ }^{a}$} \\
\hline Good & $37(74,0)$ & $7(58,3)$ \\
\hline $\begin{array}{l}\text { Neither good nor } \\
\text { poor }\end{array}$ & $10(20,0)$ & $4(33,3)$ \\
\hline Poor & $3(6,0)$ & $1(8,3)$ \\
\hline
\end{tabular}

${ }^{\text {a }}$ Missing data for two participants in full sample

Table 2 Frequency table of card ranking stability $(n=52)$

\begin{tabular}{llll}
\hline Stability & Frequency & Valid percent & $\begin{array}{l}\text { Cumulative } \\
\text { percent }\end{array}$ \\
\hline $20 \%$ & 1 & 1.9 & 1.9 \\
$29 \%$ & 1 & 1.9 & 3.8 \\
$30 \%$ & 1 & 1.9 & 5.8 \\
$33 \%$ & 1 & 1.9 & 7.7 \\
$40 \%$ & 5 & 11.5 & 19.2 \\
$50 \%$ & 8 & 13.5 & 32.7 \\
$60 \%$ & 17 & 32.7 & 65.4 \\
$70 \%$ & 10 & 19.2 & 84.6 \\
$80 \%$ & 8 & 15.4 & 100.0 \\
Total & 52 & 100.0 & \\
\hline
\end{tabular}

Sex, age, level of education, and time elapsed between interviews were not associated with stability of card rankings. We found no relationship between changes in selfreported health status between timepoints and stability of card rankings. Participants were asked in the second interview if they had used the DöBra cards since the first interview, with varying responses. No use (indicated by $42 \%$ of participants), little use (1-3 times, indicated by $23 \%$ ) or more frequent use of the cards ( $>3$ times, indicated by $29 \%$ ) between interviews was not associated with stability in rankings.

We explored if particular card statements were ranked in the top-10 in both interviews to a higher extent than others. As shown in the Supplementary File 1, the card statements that were most likely to be ranked in the top10 in both interviews, i.e. 'To be free of pain', 'Not being short of breath' and 'To have those I am close to around me', were also the card statements most frequently prioritized in general. The card statement 'Not dying alone' was less frequently ranked in the top- 10 overall, but when prioritized by an individual, it often appeared at both their timepoints. 'To be cared for by staff I feel comfortable with' is an example of a statement often prioritized $(n=34)$, but relatively seldom ranked in the top- 10 by the same participant at both timepoints.

We then examined (Fig. 2) whether a card item ranked highly among the top- 10 cards at $\mathrm{T} 1$ would be more likely to remain in the top- 10 at $\mathrm{T} 2$, compared to card statements that were lower ranked among the top-10 cards at T1. On a group level, cards with higher rankings at T1 were significantly more likely to recur among the top-10 priorities at T2, regardless of ranking (Spearman's correlation coefficient $-0.86, p=0.002$ ).

\section{Stability of wild card formulations}

Twenty-two wild cards were prioritized in the top- 10 rankings by 19 individuals at T1 and 23 wild cards by 20 participants at T2, as shown in Table 3. Six individuals formulated a wild card only at T1, and seven other participants formulated a wild card at T2 only. Wild card formulations could vary over time. Nine wild cards formulated at T1 recurred exactly or with a close formulation at T2. Four participants formulated substantially different wild cards at the two timepoints (Table 3).

\section{Stability of reasoning about ranked end-of-life preferences: same, same, but different?}

Characteristics of the 12 participants whose data provide basis for qualitative analysis are presented in Table 1. As elaborated on below, we found that similarities and differences in reasoning were not necessarily related to similarities and differences in ranked card choices; Table 4 shows an overview of this, while further exploration of participants' individual reasoning is exemplified with quotes in Table 5. 


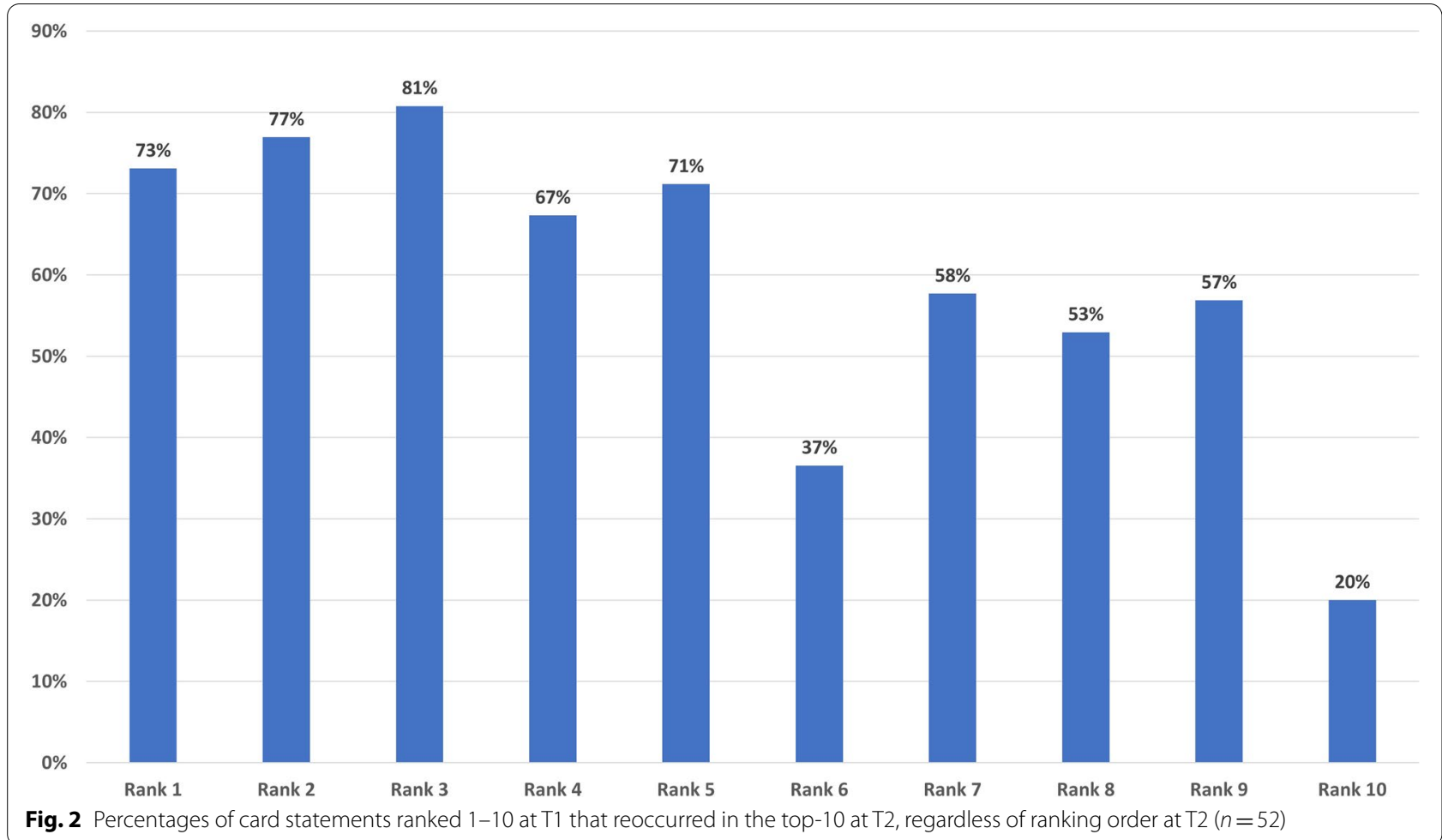

\section{Reasoning about card choices that recurred over time in rankings}

Similar reasoning about a recurring card statement in rankings at both $\mathrm{T} 1$ and $\mathrm{T} 2$ was generally characterized by the participant talking about a strong experience, opinion or habit about the preference in question (see illustrative quotes in Table 5). P9 had a profound childhood experience which the participant referred to in both interviews as influential on the choice of card statement 'Not being short of breath', while P18 chose the card statement 'To have a human touch' in both interviews based on a strong interest in tactile massage. For P53, the card statement 'To pray' was explained as self-evident in both interviews as it had been part of a life-long daily routine.

In rare cases, participants reasoned slightly differently over time about recurring card choices in rankings. For example, P7 ranked the card statement 'To be cared for by staff I feel comfortable with' in the top-10 in both interviews, but at $\mathrm{T} 2$ added nuances by problematizing the role of health care staff. P45 also showed modified reasoning about the card statement 'To have those I am close to around me' which seemed to concern the participant's own comfort at T1, while at T2 those close to the participant were considered.

\section{Reasoning about card choices that changed over time}

There were numerous occasions when participants reasoned similarly about a DöBra card statement in both interviews, although ranked it among the top-10 preferences on only one occasion. As exemplified in Table 5, neither P42 nor P18 appeared to reason differently at $\mathrm{T} 1$ and T2 about card statements that were in the top10 at only one timepoint. Similarly, P10 spoke extensively about a wish to remain at home at $\mathrm{T} 1$, although the statement 'To die at home' was a top-10 priority only at $\mathrm{T} 2$, following much briefer discussion.

There were also other variations in reasoning about card choices that changed in rankings over time. In some cases, the difference appeared to be in participants' considerations of the relative importance of an item. For example, while P53 did not motivate why humor was not included in the top-10 ranking at $\mathrm{T} 1$, at $\mathrm{T} 2$ the participant described how a recent event had highlighted its' importance. Change in importance of card items could also be due to external factors, as exemplified by P33 when retroactively explaining the top-10 ranking of 'To trust my doctor' at T1, as probably due to having a good doctor at the time.

In other situations, it appeared that the participant's definition of a card item had changed over time. 
Table 3 Overview of wild cards in both interviews

\begin{tabular}{|c|c|c|}
\hline \multicolumn{3}{|c|}{ Rank (1-10). Wild card formulation. } \\
\hline Participant \# & First interview (T1) & Second interview (T2) \\
\hline P2 & (10). To get help in ending my life when I want to & (1). That there is help for euthansia \\
\hline P5 & (10). To be able to end my life when I want to & [No wild card] \\
\hline P7 & (10). To know that someone will take care of my close ones & (1). That one can get help ending it all, in a dignified manner \\
\hline P10 & $\begin{array}{l}\text { (1). To get to decide myself when to die... I'm kind of in favor of } \\
\text { euthanasia }\end{array}$ & (1). To be entitled to euthanasia \\
\hline P12 & [No wild card] & $\begin{array}{l}\text { (10). To be able to have passive euthanasia, to not be connected to } \\
\text { life-sustaining machines, to stop treatment }\end{array}$ \\
\hline P13 & [No wild card] & (10). To get an injection and die \\
\hline P14 & (2). To have flowers around me & [No wild card] \\
\hline P18 & (1). To have room for my spirituality & [No wild card] \\
\hline P19 & (1). To have my teddy bear with me & (1). To be entitled to euthanasia \\
\hline P20 & (4). To be entitled to euthanasia & (6). To be able to communicate \\
\hline P21 & (2). To have the right to end my life myself & $\begin{array}{l}\text { (3). The right to choose a place } \\
\text { (5). To have the right to end my life }\end{array}$ \\
\hline P25 & (10). To be able to stop eating when I know the end is near & (10). To not get nutritional drinks but to let my body die naturally \\
\hline P27b & $\begin{array}{l}\text { (6). To be a partner for discussion in health care all the way to the } \\
\text { end }\end{array}$ & [No wild card] \\
\hline P28 & $\begin{array}{l}\text { (5). Not being connected to machines when you don't have a } \\
\text { life with dignity }\end{array}$ & (10). Not being connected to life-sustaining machines \\
\hline P30 & [No wild card] & (8). To not be force-fed \\
\hline P33 & (1). To be able to decide myself when to end my life & (5). Euthanasia \\
\hline P43 & [No wild card] & (4). To not have to lay there thirsty \\
\hline P45 & (2). To not have any life-sustaining measures & $\begin{array}{l}\text { (1). Nothing left to lose [spoken in English] - I don't want to have } \\
\text { any of my things left }\end{array}$ \\
\hline P48 & [No wild card] & $\begin{array}{l}\text { (4). That there are people around me, close by } \\
\text { (7). A beautiful environment }\end{array}$ \\
\hline P49 & [No wild card] & (8). To be able to decide a place myself \\
\hline P51 & $\begin{array}{l}\text { (4). To be able to eat what I like } \\
\text { (7). To have someone take responsibility for my finances }\end{array}$ & $\begin{array}{l}\text { (1). To have someone take responsibility for the finances } \\
\text { (6). Food and drink }\end{array}$ \\
\hline P53 & $\begin{array}{l}\text { (2). To have peace with God } \\
\text { (9). To get the strength to physically and mentally support my } \\
\text { wife }\end{array}$ & [No wild card] \\
\hline P57 & (1). To have the right to end my life & $\begin{array}{l}\text { (1). To get euthanasia to avoid breathlessness, pain, worry and } \\
\text { anxiety }\end{array}$ \\
\hline P58 & $\begin{array}{l}\text { (1). To be able to give love to those I meet, until the end } \\
\text { (2). To convey courage and confidence }\end{array}$ & $\begin{array}{l}\text { (1). To be able to spread peace, love and contentment to others up } \\
\text { to the very end }\end{array}$ \\
\hline P59 & (1). To have the opportunity of assisted living & [No wild card] \\
\hline P61 & [No wild card] & (6). To wear my own clothes \\
\hline
\end{tabular}
Phrases in bold indicate wild card formulations which adjusted existing DöBra card formulations. Four participants formulated five additional wild cards which were not included in their top-10 ranking and therefore not presented here

Table 4 Overview of types of reasoning about identical/changed card choices

\begin{tabular}{|c|c|c|}
\hline & Similar reasoning & Changed reasoning \\
\hline Identical card choice & $\begin{array}{l}\text { - Profound experiences } \\
\text { - Strong opinions } \\
\text { - Habits }\end{array}$ & $\begin{array}{l}\text { - Added nuances } \\
\text { - Modified argumentation }\end{array}$ \\
\hline Changed card choice & $\begin{array}{l}\text { - Similar reasoning that did not explain the change in card choice } \\
\text { - Change in relative importance of card item }\end{array}$ & $\begin{array}{l}\text { - Change in definition of } \\
\text { card item } \\
\text { - Issue had been resolved } \\
\text { between timepoints }\end{array}$ \\
\hline
\end{tabular}




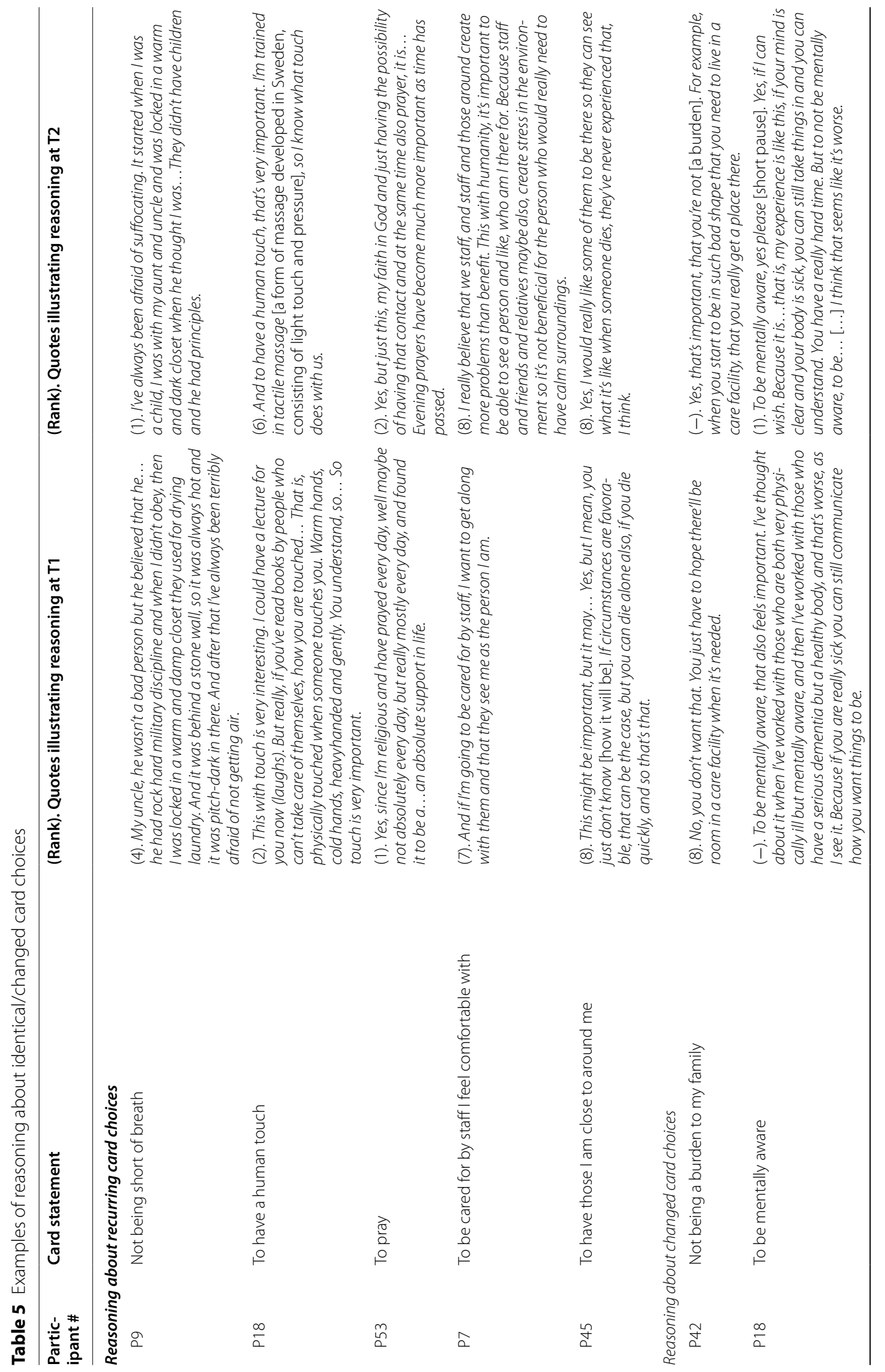




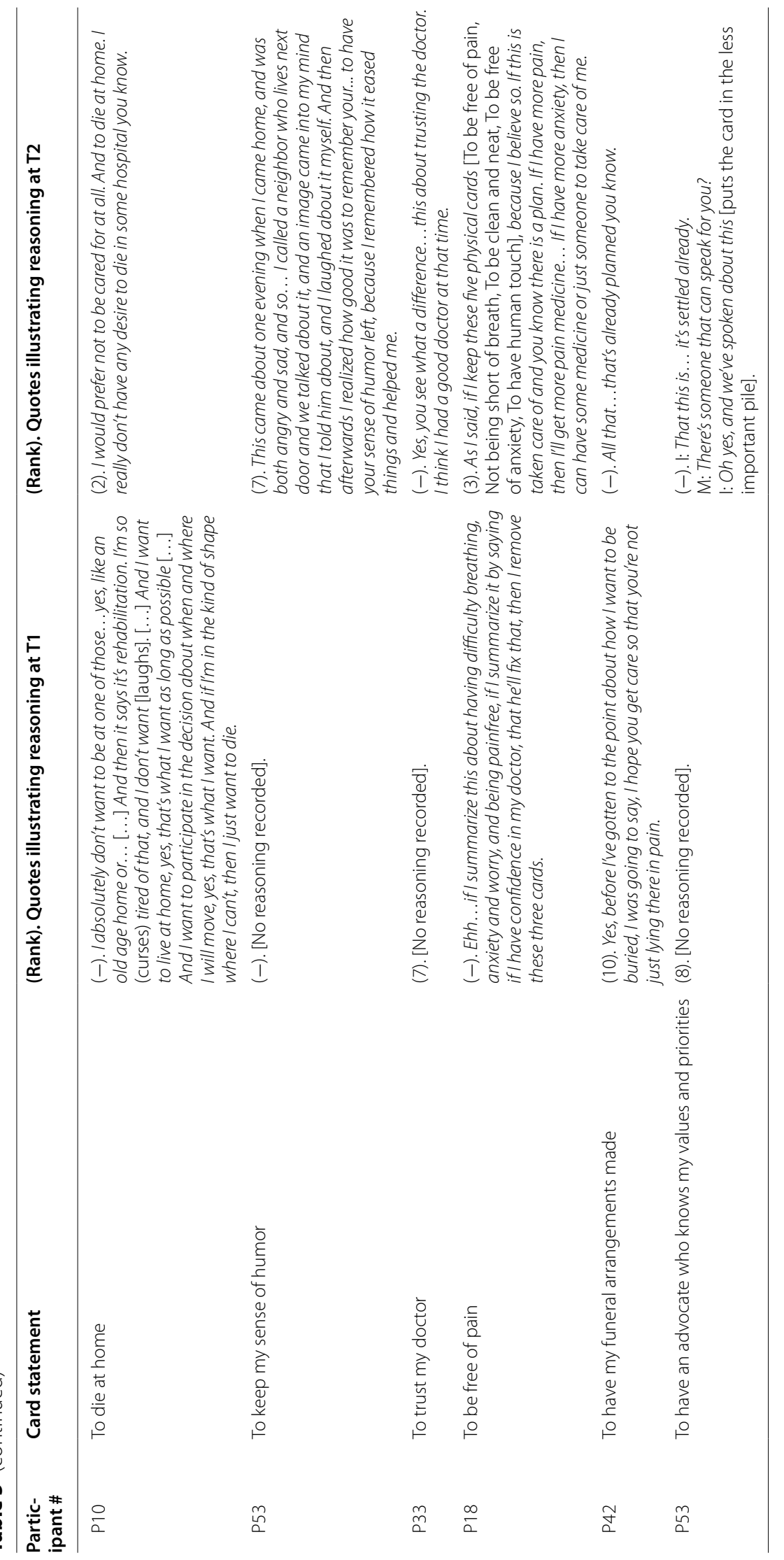


Participants sometimes considered interrelationships and overlap between card statements which led them to define and prioritize items differently in the two interviews. This is exemplified by P18 who ranked 'To trust my doctor' in the top- 10 at T1 with the motivation that that choice would cover also pain, breathing and anxiety, card items which were included in the participant's top10 ranking at $\mathrm{T} 2$ only.

As exemplified by P42 and P53, another type of reasoning may indicate that if an issue had been resolved between interviews, it was considered less important at $\mathrm{T} 2$.

\section{Discussion}

This study explores stability in ranking and reasoning about end-of-life values and preferences among community-dwelling older adults, using the Swedish DöBra cards to stimulate reflection and discussion in interviews 5.5-12 months apart. As might be expected, on a group level the most frequently prioritized card items at $\mathrm{T} 1$ were also those more likely to recur. Individual characteristics, i.e. demographic variables, change in self-reported health status, time elapsed or degree of card use between interviews, were not related to stability in card rankings. Through qualitative analysis, we found that consistent reasoning was not always paired with consistency in ranked card choices and changes in ranked card choices were not always related to changes in reasoning. Strong experiences or habits seemed influential when both reasoning and ranked card choices recurred over time, while changes in card choices could be explained by participants' changing views of the definition or relative importance of a card item between timepoints.

In this study, a median stability of individual, ranked future end-of-life care preferences and priorities of $60 \%$ was found. This is comparable to that found in other studies measuring GoWish card ranking stability over time [22, 23]. Our findings differ somewhat from Delgado-Guay et al's U.S. study [23], where the two most frequently ranked cards in the top-10 at both timepoints were related to religion, while in this Swedish study, conducted in a country known to be secular [34], on group level the top two ranked cards were related to physical comfort. In both studies, the card statement 'to have those I am close to/my family with me' was in third place in these rankings. However, in Delgado-Guay et al.s study [23], it is not possible to determine whether the same individual ranked the card item in both interviews, which is a strength of the study presented here. As we have previously reported $[25,35]$, the relatively frequent use of wild card formulations about assisted dying in this sample is unique for studies using the GoWish cards. The present study contributes with knowledge about how preferences related to assisted dying also are subject to change over time.

The concept of response shift may be helpful in understanding these data. Response shift is defined as changes in respondents' internal standards ("recalibration"), values ("reprioritization"), and/or definition of the target concept ("reconceptualization") [36]. While we have shown examples of both reconceptualization and reprioritization, these data do not allow stringent investigation of recalibration. However, the lower rate of consistency among cards ranked lower in the top-10 at $\mathrm{T} 1$ compared to T2 (Fig. 2) may suggest a form of recalibration. It is possible that a card item may maintain both its definition and level of importance but no longer be in the top-10 if other card items have become more important, thus expanding the scale.

Preston et al. [37] suggest that in considering response shift, end-of-life clinicians should devote attention to exploring individuals' 'anchor values'. We found that profound values/preferences connected to strong habits or important life experiences were more likely to be stable over time, and when these clearly resonated with a card statement, that card would typically be prioritized in the top-10 ranking at both timepoints. As suggested also by our previous work [35] and other studies [38, 39], these findings provide further support for an iterative process of ACP, focusing on conversations about individuals' anchor values rather than solely documenting medical treatment preferences. Others in the field $[40,41]$ argue for the importance of timely and repeated ACP discussions to allow for both advance as well as in the moment decisions.

\section{Strengths and limitations}

Strengths of this study thus include the combination of exploring DöBra card rankings as well as underlying reasoning about end-of-life preferences over time, which furthers knowledge on the dynamics between values and preferences in end-of-life decision-making [42, 43]. Other strengths are the longitudinal design with communitydwellers in a natural setting with end-of-life preferences defined broadly, design choices also suggested by others $[11,38]$, as opposed to researcher-formulated hypothetical illness scenarios. Limitations include a larger risk of a type II error due to the relatively small sample size. The heterogeneity of the sample limits drawing conclusions based on statistical findings; however, our findings suggest that individual variation in card rankings would in itself discourage drawing such conclusions.

As self-reported health status may also be subject to response shift, exploring stability in relation to illness or life events would have been desirable. However, the lack of comprehensive, systematic data about possible illness 
progression or other life events between interviews in these data limits our ability to relate changes in preferences to such events. We did note that while two of the six participants lost to attrition reported their health state to be 'neither good nor poor' at the 1st interview, as group sizes were small we refrain from drawing conclusions based on this. Further research on end-of-life values and preferences in community-dwellers beyond the time-period reported on in this study would be valuable to increase knowledge about if, how, and when end-oflife values and preferences change over time.

In conclusion, our study suggests that there are different aspects that are indicative of stability of older adults' values and preferences for future end-of-life care. Based on an intuitive ACP conversation-based card game, selection and ranking of the most important card items is relatively stable over time albeit with large variation between individuals. The values and underlying reasoning that participants used to motivate their choices appear more stable than ranking of card choices. We thus conclude that concurrent conversation-based exploration is a more comprehensive indicator of an individual's endof-life values and preferences over time than ranking of cards alone.

\section{Abbreviations \\ ACP: Advance care planning; SweACP: "Advance care planning in Sweden" (project name).}

\section{Supplementary Information}

The online version contains supplementary material available at https://doi. org/10.1186/s12904-021-00839-7.

Additional file 1. Overview of participants' card choices.

Additional file 2. Supplemental demographic information.

\section{Acknowledgements}

The authors would like to acknowledge the important contribution of Olav Lindqvist, RN, PhD, who was PI for this project until his death from a sudden cardiac event in March 2018. We would also like to acknowledge Sara Runesdotter's invaluable assistance in statistical testing and the contributions of the SweACP project group members, including Therese Johansson's contribution to data collection. Furthermore, we thank Dr. Elizabeth S. Menkin, Prof. Joachim Cohen and Prof. Lieve Van den Block for their generous feedback on this manuscript.

\section{Authors' contributions}

Authors ME, GH, CT were all involved in designing the study, discussing analysis and finishing the manuscript. ME performed data collection, was main responsible for analysis and drafted the first versions of the manuscript. The author(s) read and approved the final manuscript.

\section{Funding}

This work was supported by Swedish Research Council for Health, Welfare and Working Life; Doctoral School for Health Care Sciences at Karolinska Institutet; Vårdal Foundation; Göteborg Center for Person-Centered Care; Strategic Research Area Health Care Sciences at Karolinska Institutet and Umeå University; The Dementia Foundation; Ulrika Cronés Foundation; and
Sahlgrensringen Foundation. Author CT's position was supported by an endowment from Investor AB. Open access funding provided by Karolinska Institutet.

\section{Availability of data and materials}

The datasets analyzed during the current study are not publicly available due to restraints of the ethical permit, some data may be available from the corresponding author upon reasonable request.

\section{Declarations}

\section{Ethics approval and consent to participate}

This study was approved by the regional ethical review board in Stockholm (Stockholm, \#2015/106-31/5) and the study was carried out in accordance with relevant guidelines and regulations. Participants gave their written informed consent prior to enrollment in the study.

\section{Consent for publication}

Not applicable.

\section{Competing interests}

The authors declare that they have no competing interests.

\section{Author details}

${ }^{1}$ Department of Learning, Informatics, Management and Ethics, Karolinska Institutet, 17177 Stockholm, Sweden. ${ }^{2}$ Department of Health, Education and Technology, Luleå University of Technology, Luleå, Sweden. ${ }^{3}$ Stockholm Health Care Services (SLSO), Region Stockholm, Stockholm, Sweden. ${ }^{4}$ University of Southampton, School of Health Sciences, Southampton, UK.

Received: 5 March 2021 Accepted: 2 September 2021

Published online: 22 September 2021

References

1. Rietjens JAC, Sudore RL, Connolly M, van Delden JJ, Drickamer MA, Droger $\mathrm{M}$, et al. Definition and recommendations for advance care planning: an international consensus supported by the European Association for Palliative Care. Lancet Oncol. 2017;18(9):e543-e51.

2. Sellars M, Clayton J, Detering K, Tong A, Power D, Morton R. Costs and outcomes of advance care planning and end-of-life care for older adults with end- stage kidney disease: a person-centred decision analysis. PLoS One. 2019;14(5):e0217787.

3. Brinkman-Stoppelenburg A, Rietjens JA, van der Heide A. The effects of advance care planning on end-of-life care: a systematic review. Palliat Med. 2014;28(8):1000-25.

4. Pollak Kl, Gao X, Beliveau J, Griffith B, Kennedy D, Casarett D. Pilot study to improve goals of care conversations among hospitalists. J Pain Symptom Manag. 2019;58(5):864-70.

5. Levoy K, Salani DA, Buck H. A systematic review and gap analysis of advance care planning intervention components and outcomes among cancer patients using the transtheoretical model of health behavior change. J Pain Symptom Manag. 2019;57(1):118-39.

6. van Wijmen MPS, Pasman HRW, Twisk JWR, Widdershoven GAM, Onwuteaka-Philipsen BD. Stability of end-of-life preferences in relation to health status and life-events: a cohort study with a 6-year follow-up among holders of an advance directive. PLoS One. 2018;13(12):e0209315.

7. Choi JJ, Kim SH, Kim SW. Reversals in decisions about life-sustaining treatment and associated factors among older patients with terminal stage of cardiopulmonary disease. J Korean Acad Nurs. 2019;49(3):329-39.

8. Tang ST, Wen FH, Chang WC, Hsieh CH, Chou WC, Chen JS, et al. Preferences for life-sustaining treatments examined by hidden Markov modeling are mostly stable in terminally ill cancer patients' last six months of life. J Pain Symptom Manag. 2017:54(5):628-36.

9. Houben CHM, Spruit MA, Schols J, Wouters EFM, Janssen DJA. Instability of willingness to accept life-sustaining treatments in patients with advanced chronic organ failure during 1 year. Chest. 2017;151(5):1081-7.

10. Tang ST, Wen FH, Hsieh CH, Chou WC, Chang WC, Chen JS, et al. Preferences for life-sustaining treatments and associations with accurate 
prognostic awareness and depressive symptoms in terminally ill cancer patients' last year of life. J Pain Symptom Manag. 2016;51(1):41-51.

11. Auriemma CL, Nguyen CA, Bronheim R, Kent S, Nadiger S, Pardo D, et al. Stability of end-of-life preferences: a systematic review of the evidence. JAMA Intern Med. 2014;174(7):1085-92.

12. Jabbarian L, Maciejewski RC, Maciejewski PK, Rietjens JA, Korfage I, Heide A, et al. The stability of treatment preferences among patients with advanced cancer. J Pain Symptom Manag. 2019;57(6):1071-9.

13. Gallo JJ, Abshire M, Hwang S, Nolan MT. Advance directives, medical conditions, and preferences for end-of-life care among physicians: 12-year follow-up of the Johns Hopkins precursors study. J Pain Symptom Manag. 2019;57(3):556-65.

14. Barrio-Cantalejo IM, Simón-Lorda P, Molina-Ruiz A, Herrera-Ramos F, Martínez-Cruz E, Bailon-Gómez RM, et al. Stability over time in the preferences of older persons for life-sustaining treatment. J Bioeth Inq. 2013;10(1):103-14.

15. Bolt EE, Pasman HRW, Deeg DJH, Onwuteaka-Philipsen BD. From advance euthanasia directive to euthanasia: stable preference in older people? J Am Geriatr Soc. 2016;64(8):1628-33.

16. Lindqvist O, Tishelman C. Going public: reflections on developing the DöBra research program for health-promoting palliative care in Sweden. Prog Palliat Care. 2016;24(1):19-24.

17. Menkin ES. Go wish: a tool for end-of-life care conversations. J Palliat Med. 2007;10(2):297-303.

18. Regionala cancercentrum i samverkan. Nationellt vårdprogram Palliativ vård i livets slutskede. Stockholm: RCC Samverkan; 2016.

19. Zwakman M, Jabbarian $L$, van Delden JJM, van der Heide A, Korfage IJ, Pollock K, et al. Advance care planning: a systematic review about experiences of patients with a life-threatening or life-limiting illness. Palliat Med. 2018;32(8):1305-21.

20. Somes E, Dukes J, Brungardt A, Jordan S, DeSanto K, Jones $C$, et al. Perceptions of trained laypersons in end-of-life or advance care planning conversations: a qualitative meta-synthesis. BMC Palliat Care. 2018;17(1):98

21. Vearrier $L$. Failure of the current advance care planning paradigm: advocating for a communications-based approach. HEC Forum. 2016;28(4):339-54.

22. Siefman M, Brummel-Smith K, Baker S. Consistency of choices of end-of-life wishes using the "go wish" cards: a comparison of elders with intact cognition and mild cognitive impairment. J Am Geriatr Soc. 2013;61(s1):s120.

23. Delgado-Guay MO, Rodriguez-Nunez A, De la Cruz V, Frisbee-Hume S, Williams J, Wu J, et al. Advanced cancer patients' reported wishes at the end of life: a randomized controlled trial. Support Care Cancer. 2016;24(10):4273-81.

24. Ray RA, Street AF. Ecomapping: an innovative research tool for nurses. J Adv Nurs. 2005;50(5):545-52.

25. Tishelman C, Eneslätt M, Menkin E, Lindqvist O. Developing and using a structured, conversation-based intervention for clarifying values and preferences for end-of-life in the advance care planning-naiive Swedish context: action research within the DöBra research program. Death Stud. 2019.

26. Lankarani-Fard A, Knapp H, Lorenz KA, Golden JF, Taylor A, Feld JE, et al. Feasibility of discussing end-of-life care goals with inpatients using a structured, conversational approach: the go wish card game. J Pain Symptom Manag. 2010;39(4):637-43.
27. Street AF, Blackford J, Threlkeld G, Bidstrup B, Downing J. Entrust-U: evaluative life review and advance care planning. Wodonga: LaTrobe University; 2011.

28. Tatlow K. Communicating my values, my wishes: advance care planning in community palliative care. BMJ Support Palliat Care. 2013;3(2):257.2.

29. Zachariah F, Klein L, Clifton-Hawkins N, Andrews M, Gross D. "It's about the conversation": a multidisciplinary intervention to support advance care planning (S808). J Pain Symptom Manage. 2015;49(2):464.

30. O'Cathain A, Murphy E, Nicholl J. The quality of mixed methods studies in health services research. J Health Serv Res Policy. 2008;13(2):92-8.

31. Saldaña J. Longitudinal qualitative research: analyzing change through time. Walnut Creek: Rowman \& Littlefield Pub Incorporated; 2003.

32. Sandelowski M. Casing the research case study. Res Nurs Health. 2011;34:153-9.

33. Malterud K, Siersma VD, Guassora AD. Sample size in qualitative interview studies: guided by information power. Qual Health Res. 2016;26(13):1753-60.

34. Tomasson RF. How Sweden became so secular. Scand Stud. 2002;74(1):61-88.

35. Eneslätt M, Helgesson G, Tishelman C. Exploring community-dwelling older adults' considerations about values and preferences for future endof-life care: a study from Sweden. The Gerontologist. 2020;6(17):1332-42.

36. Sprangers MA, Schwartz CE. Integrating response shift into healthrelated quality of life research: a theoretical model. Soc Sci Med. 1999:48(11):1507.

37. Preston NJ, Fayers P, Walters SJ, Pilling M, Grande GE, Short V, et al. Recommendations for managing missing data, attrition and response shift in palliative and end-of-life care research: part of the MORECare research method guidance on statistical issues. Palliat Med. 2013;27(10):899-907.

38. Etkind SN, Lovell N, Nicholson CJ, Higginson IJ, Murtagh FE. Finding a 'new normal' following acute illness: a qualitative study of influences on frail older people's care preferences. Palliat Med. 2019;33(3):301-11.

39. Combes S, Nicholson CJ, Gillett K, Norton C. Implementing advance care planning with community-dwelling frail elders requires a system-wide approach: an integrative review applying a behaviour change model. Palliat Med. 2019;33(7):743-56.

40. Moody SY. "Advance" care planning reenvisioned. J Am Geriatr Soc. 2021:69(2):330-2

41. Bradshaw A, Bayly J, Penfold C, Lin C-P, Oluyase AO, Hocaoglu MB, et al. Comment on: "advance" care planning reenvisioned. J Am Geriatr Soc. 2021;69(5):1177-9.

42. Evans N, Pasman HR, Deeg D, Onwuteaka-Philipsen B. How do general end-of-life treatment goals and values relate to specific treatment preferences? A population-based study. Palliat Med. 2014;28(10):1206-12.

43. Howard M, Bansback N, Tan A, Klein D, Bernard C, Barwich D, et al. Recognizing difficult trade-offs: values and treatment preferences for end-of-life care in a multi-site survey of adult patients in family practices. BMC Med Inform Decis Mak. 2017;17:164.

\section{Publisher's Note}

Springer Nature remains neutral with regard to jurisdictional claims in published maps and institutional affiliations.

\footnotetext{
Ready to submit your research? Choose BMC and benefit from:

- fast, convenient online submission

- thorough peer review by experienced researchers in your field

- rapid publication on acceptance

- support for research data, including large and complex data types

- gold Open Access which fosters wider collaboration and increased citations

- maximum visibility for your research: over 100M website views per year
}

At BMC, research is always in progress.

Learn more biomedcentral.com/submissions 